\title{
An Overview of Chinese Pangolin (Manis pentadactyla): Its General Biology, Status, Distribution and Conservation Threats in Nepal
}

\author{
Prakash Thapa ${ }^{1}$ \\ Email: Prakash.thapa68@gmail.com
}

\begin{abstract}
Chinese Pangolin is nocturnal, shy, non-aggressive, solitary, strange and burrowing mammal which has received low scientific attention. Little information is known about its biology, distribution and status. In Nepal it is distributed in many districts and protected areas. The status of this mammal is decreasing in the country but there is no any research regarding its biology, status and distribution. Although, this mammal is protected nationally and internationally, it is facing too much problems due to habitat destruction and illegal trade. This article mainly focuses on the biology, status, distribution and conservation threats of this ecologically beneficial handsome creature.
\end{abstract}

Key Words: Chinese Pangolin, Status, Distribution, Biology, Threats

\section{Introduction}

Pangolin, a less scientific attention received species, is a strange small mammal with some typical morphological characteristics which belongs to genus Manis.

The word "Pangolin" is French origin derived from Malayan phrase, "Pen Gulling" belonging to the animal ability to curl up into a ball. Pangolin, often called "scaly anteater," is covered with tough, overlapping scales. It is a nocturnal, shy, non-aggressive and solitary animal.

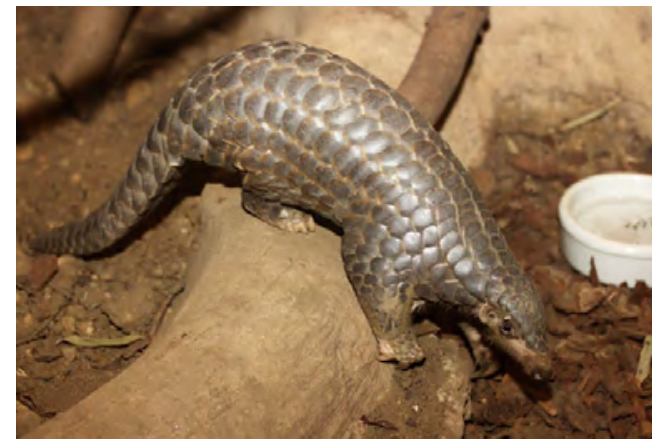

Figure 1: Chinese Pangolin

${ }^{1}$ Student, Kathmandu Forestry College 
Eight different types of Pangolins are found in the world which are broadly classified as Asian Pangolins and African Pangolins.

The Asian Pangolins include:

1. Indian or Thick-tailed Pangolin (Manis crassicaudata)

2. Chinese or Formosan Pangolin (Manis pentadactyla)

3. Malayan or Sunda Pangolin (Manis javanica)

4. Palawan or Philippine Pangolin (Manis culionensis)

The African Pangolins include:

1. Giant Pangolin (Manis gigantean)

2. Cape Pangolin (Manis temminckii)

3. Long-tailed Pangolin (Manis tetradactyla)

4. Tree Pangolin (Manis tricuspis)

Nepal lies on the transition zone of the oriental and palearctic regions, so there is occurrence of both the Chinese and Indian species in Nepal (Shrestha, 1981). The generic name of Pangolin in Nepal is "Salak" although it has some local names that are popular in particular areas. For instance, it is called "Kaynaya"(Newari language),"Kose" (Tamang language) and "Hilemaccha" in hill by the virtue of its bronze like overlapping scales (Kaspal, 2008).

\section{General Classification}

The general classification of Chinese Pangolin is as follows:

Kingdom : Animalia

Phylum : Chordata

Subphylum : Vertebrata

Class : Mammalia

Order : Pholidota

Family : Manidae

Genus : :Manis

Species : pentadactyla 


\section{General Biology}

\section{a. Habitat}

Manis pentadactyla is found in a wide range of habitats, including primary and secondary tropical forests, limestone forests, bamboo forests, agricultural fields and grasslands (Chao Jung-Tai 1989; Gurung 1996: as cited in IUCN red list). It is a burrowing species which use its strong, clawed forefeet to dig burrows.

\section{b. Physical Characteristics}

It has a streamlined body with a long tail. The body is covered with protective, overlapping, fifteen to eighteen rows of scales. The scales grow throughout the life. The scales are accompanied by hairs. It measures around $60 \mathrm{~cm}$ from head to body with an $18 \mathrm{~cm}$ tail. Sexual dimorphism is present in this species. It has a small pointed head and a narrow mouth. The nose is fleshy and has nostrils at the end. The forefeet and hind feet are equipped with sharp claws. Due to poor vision, they locate termite and ant nests with their strong sense of smell. Teeth are absent in Pangolins but they possess long tongue.

\section{Behavior}

Being solitary, nocturnal and highly secretive mammal, it is difficult for scientists to study in the wild and many mysteries remain about its behavior and habits. Chinese Pangolin sleeps in underground burrows during the day. It is a shy, non aggressive and slow moving creature which emerges in the evening to forage for insects. Chinese Pangolin defends itself by curling up into a ball and is also protected from predators by the hard scales which cover the body.

\section{d. Food}

Pangolin lives on a diet of ants and termites. This special diet makes Pangolin extremely difficult to maintain in captivity.

\section{e. Reproduction}

Chinese Pangolin reproduces during April and May. A single young is born measuring about $45 \mathrm{~cm}$ and weighing about $1 \mathrm{lb}$. The young come equipped with scales, although they are soft and flexible for the first two days of life. Although they are able to walk at birth, young Pangolins are carried on their mother's tail or back. If the mother is threatened, she folds her offspring under her body with her tail. Male Pangolin has been observed to exhibit remarkable parental instincts and share a burrow with the female and young. 


\section{f. Life Span}

It is unknown how long Pangolin can live in the wild, though Pangolin has reportedly lived as long as twenty years in captivity (http://www.savePangolins.org/what-is-a-Pangolin/). According to the record of central zoo, Jawalakhel, its survival rate was low in zoo with longest survival of nine months.

\section{g. Ecological Importance}

Pangolin feeds almost exclusively on ant and termites, so it plays an essential role in keeping these populations under control. According to the Save Pangolins organization, an average adult Pangolin eats more than 70 million individual insects each year, meaning that if they were removed from a particular habitat, insect populations could rise and upset the delicate balance of the local ecosystem. Also, Pangolin is a burrowing animal so it provides a shelter for large number of animals. Thereby helps to increase species diversity. So, Pangolin has great role in ecological balance.

\section{Status}

Virtually, there is no any information regarding their population in the world. Although they are traded in international market, little is known about their ecology and rarely reported in biological surveys. In Nepal, their status is relatively unknown because they have received a little scientific attention.

Acharya et al. (1993) conducted survey in Nagarjun forest in Central Nepal and found six freshly dug burrows below Jamachowk in south facing sloppy area. Gurung (1996) had found fifty burrows along a four kilometer stretch of roadside at Raniban. He had noted the similarities of Pangolin habitat in Nagargun with the reports from Tumlingtar of Sankhuwasabha, Chainpur of Dhading and Belephi of Sindhupalchowk. Shrestha (2005) had done study about Pangolin in Shivapuri National Park and found the burrows in red soil at open forests with less coverage. The study conducted by Kaspal (2008) in community forests of SuryaBinayak Range post, Bhaktpur found fifty one Pangolins burrows. These burrows were mostly found in loamy (brown) and red soil in open forest with less ground coverage at south facing slope in all type of habitat. Similarly, Suwal (2011) conducted research on status, distribution, behavior and conservation of Pangolins in private and community forests of Balthali in Kavre. She found a total of 180 new burrows and 220 old burrows. Besides these research works, there is no any research upon the Chinese Pangolin in Nepal. So, the clear status of Pangolin in Nepal is unknown but the trend is decreasing due to habitat destruction and illegal trade.

\section{Distribution}

This species occurs in the Himalayan foothills in eastern Nepal, Bhutan and northern India, northeastern Bangladesh, across Myanmar to northern Lao PDR and northern Viet Nam, 
northern and northeastern Thailand and through southern China (south of the Chiangjiang) to Hainan and Taiwan (IUCN red list).

In Nepal, Chinese Pangolins are reported in various parts of country although there is no any detailed study carried out about their status, distribution and other information. It is distributed in Annapurna Conservation Area and Makalu Barun National Park. Also reported from districts of Taplejung, Illam, Panchtahar, Ramechap and Sindhulli (Majupria and Majupuria, 2006). It is known to occur in Ramechap, Pannauti (Beber area), Soondarijal, Barabisse, and Baglung (Shrestha, 1981). Also, the study made by Kaspal (2008) showed its presence in community forest of Suryabinayak range post, Bhakatapur. Similarly, the study of Suwal (2011) showed its occurrence in private and community forests of Balthali, Kavre. The research carried about Chinese Pangolin is little so there is no any data regarding its distribution.

\section{Conservation Status}

Chinese Pangolin is listed as protected mammal of Nepal under the National park and Wildlife conservation Act, 1972. So, there is a provision of fine of forty thousand NRs to seventy five thousand NRs or jail from one year to ten years or both upon the illegal killing of this protected mammal according to this act. Also it is listed in Appendix II of CITES and as Endangered in IUCN Red list of Threatened Species. Since July 2000, there is a zero export quota for Chinese Pangolin which means that its international trade is banned.

\section{Reasons of Illegal trade}

The reasons for illegal trade of Chinese Pangolin are as follows:

- The meat is used as a local source of protein.

- $\quad$ Foetuses are used for traditional medicine.

- $\quad$ The scales are used in traditional medicine, as well as for the production of souvenirs.

- The blood is used in traditional medicine and can be found in restaurants.

- $\quad$ Stuffed Pangolins are sold as souvenir.

- $\quad$ The skin is used for the production of leather accessories such as bags and shoes. (Source: Suon Phalla)

\section{Conservation Threats of Chinese Pangolin in Nepal:}

1. Habitat Destruction: Habitat destruction is one of the major conservation threats of Chinese Pangolin in Nepal. Rapid deforestation, Construction of motor able roads in hilly areas, urbanization etc. are leading to the destruction of habitat of Chinese Pangolins. 
2. Illegal Trade: Illegal Trade of live Pangolin or its parts is also major threat for conservation. Nowadays, there is tremendous increase in trade of Chinese Pangolin. Recently, a man was captured with fifty kilogram of Pangolin scales in China border. Also, a live Pangolin was caught from a man in Kathmandu (The Himalayan Times, 2012). This shows that the illegal trade has flourished in Nepal.

3. Local Use: Pangolin is locally used as a source of meat by the villagers. There are several local traditional thinking which are the major driver for the decline in Pangolin population.

4. Lack of Information and knowledge: Very little is known about the Pangolin ecology, behavior, distribution, status and other information in Nepal. There is limited scientific study of this species. So this information lacking is also the major conservation threat.

5. Predation: However due to predation Chinese Pangolins are in threats. Leopards, Tiger, Wild Dogs, Pythons, Human, etc. are the predators of Chinese Pangolins.

6. Use of Pesticides: Due to the use of pesticides in agricultural crops, Chinese Pangolins are in loss. As Pangolins main diet is ant and termites, when they are killed by use of pesticides there will be lower number of Pangolin due to food shortage.

\section{Others}

- $\quad$ Slow reproduction rate

- $\quad$ Land modification

However, the ways for mitigating these threats can be followings:

1. Promoting Organic Farming

2. Establishment of reserves within the Pangolin habitats to prevent disturbances

3. Controlling habitat destruction

4. Strong law enforcement

5. Soil mining should be controlled

6. Formation of Pangolin Conservation groups at grass root level

7. Support to the researchers to conduct research upon this less scientific attention received species

\section{Conclusion}

Chinese Pangolins are ecologically beneficial but they are receiving less scientific attention. Their biology, distribution, and status are relatively unknown. Only few researches had carried out on Chinese Pangolin in Nepal. But illegal trade in Pangolins has flourished more rapidly. So to conserve this non-aggressive species further steps should be taken to prevent their extinction. 


\section{References}

Acharya, P., Rana, K., Devkota, M., and Gurung, Y. 1993. A report on conservation status of Pangolins in the protected forest of Nagarjune, Tiger paper, Vol.3, No.1, Pp35-38.

Gurung, J.B. 1996. A Pangolin Survey in Royal Nagarjung Forest in Kathmandu, Nepal. Tiger paper 23(2): 29-32.

IUCN. 2012. IUCN Red List of Threatened Species. [http://www.iucnredlist.org/ details/12764/0] Accessed in 12 August 2012.

Kaspal, P. 2010. Saving the Pangolins: Ethno zoology and Pangolin conservation awareness in human dominated landscapes of Nepal. In A. Shrestha, S. Shrestha, S. Dahal, R. kafle, A. Thapa, T. L. Suwal, B. Timilsina and R. Ghimire (Eds.), Proceedings of First One day National Seminar on Small Mammals Issues (pp 44-58). Lalitpur, Nepal.

Kaspal, P. 2008. Status, distribution, habitat utilization and conservation of Chinese Pangolin in the community forests of suryabinayak range post, Bhaktapur district. M.Sc. Thesis, Khowpa college, T.U affiliated, Nepal

Majupuria, T.C. \& Majupuria, R.K. 2006. Wildlife and Protected areas of Nepal. S.Devi, India. pg.105

Newton, P. 2007. Potential applications of hunters' knowledge for the conservation of Pangolins in Vietnam. M.Sc. Thesis, University of East Angila, Norwich.

Pangolin conservation stakeholders workshop, Combodia, participants hands out, November $4^{\text {th }}$ and $5^{\text {th }}$, 2008. Available from http://www.savePangolin.org

Phalla, S.2008.Conservation and Management of Pangolins in Cambodia. In S. Pantel and

S.Y. Chin (Eds.),Proceedings of the Workshop on Trade and Conservation of Pangolins Native to South and Southeast Asia (pp 44-48). TRAFFIC Southeast Asia, Petaling Jaya, Selangor, Malaysia.

Raynor, S. 2000. "Manis pentadactyla" (On-line), Animal Diversity Web. Accessed August 01,http://animaldiversity.ummz.umich.edu/site/accounts/information/Manis_ pentadactyla.html

Shrestha, T.K. 1981. Wildlife of Nepal. Astudy of Renewable Resources of Nepal, Himalayas. Curriculum Development Center. T.U. Kathmandu. pg.244 Suwal, T.L. 2011. Status, distribution, behavior and conservation of Pangolins in private andcommunity forests of Balthali in Kavre, Nepal. M.Sc. Thesis, Tribhuwan University, Nepal

The Himalayan Times. 2012. Man arrested with Pangolin. The English Daily. Published at July 9, 2012 (http://www.thehimalayantimes.com/) http://Pangolins.org/2012/04/18/ meet-the-chinese-Pangolin http://www.savePangolin.org 